\title{
Gabriel García Márquez, Mario Vargas Llosa y la tematización de la masacre de las bananeras
}

Cómo citar

este artículo en APA:

López, A. (2017).

Gabriel García Márquez,

Mario Vargas Llosa

y la tematización de

la masacre de las

bananeras. Analecta

Política, 7(13), 333-355.

\section{Recibido:}

10 de abril de 2017

Aprobado:

15 de agosto de 2017
Gabriel García Márquez, Mario Vargas Llosa, and the Thematization of The Banana Massacre

Gabriel García Márquez, Mario Vargas Llosa e a tematização da massacre das plantações de banana

\section{ANDRÉS FELIPE LÓPEZ LÓPEZ}

Doctor en Filosofía por la Universidad Pontificia Bolivariana de Medellín-Colombia. Profesor en la Universidad de San Buenaventura de Medellín, en la Universidad Pontificia Bolivariana de la misma ciudad y en Universidad Católica de Oriente. El artículo presenta el resultado de la investigación Gabriel García Márquez, Mario Vargas Llosa y la tematización de la masacre de las bananeras. Ensayo de una descripción histórica y económicopolitica, vinculada al grupo FACEA de la Universidad Católica de Oriente. Correo electrónico: andres.lopez@usbmed.edu. co. orcid.org/0000-0002-4298-8446. Dirección postal: Carrera 81c no. 49 - 74, C.P. 050035, Medellín - Colombia. 
Gabriel García Márquez, Mario Vargas Llosa y la tematización...

\section{Resumen}

La obra literaria de Gabriel García Márquez, la misma que estudiara Mario Vargas Llosa para su tesis doctoral en la Facultad de Filosofía y Letras de la Universidad Complutense, tiene como trasfondo hechos relevantes de la historia económica y política de Colombia. Uno de estos es la masacre de las bananeras de 1928. El estudio literario e histórico de la misma obra permite hacer el mapa de la vida social-económica del país, con énfasis en una parte concreta de la sociedad colombiana y en un dominio de tiempo específico: el departamento del Magdalena, por un lado, y los principios del siglo XX, por otro.

\section{Palabras clave}

Gabriel García Márquez, Mario Vargas Llosa, historia, política, literatura.

\section{Abstract}

The literary work of Gabriel García Márquez -which was studied by Mario Vargas Llosa as a graduate student at Complutense University of Madrid- has as background key events of the economic and political history of Colombia, being one of these events the Banana Massacres in 1928. A literary and historical analysis of this work makes possible to elaborate a map of the socio-economic life of the country, highlighting a specific region of Colombian society and a specific period: on the one hand, the state of Magdalena, and, on the other, the beginnings of the 20th century.

\section{Key words}

Gabriel García Márquez, Mario Vargas Llosa, history, politics, literature.

\section{Resumo}

A obra literária de Gabriel García Márquez, a mesma que estudaou Mario Vargas Llosa para a sua tese de doutorado na Faculdade de Filosofia e Letras da Universidade Complutense, tem como pano de fundo factos importantes da história econômica e política da Colômbia. Um deles, e a massacre das plantaçôes de banana de 1928 . $\mathrm{O}$ estudo literário e histórico da mesma obra, permite fazer o mapa da vida social e económica do país, com ênfase numa parte concreta da sociedade colombiana e num domínio de tempo específico: o departamento de Magdalena, de um lado, e o início do século XX, do outro.

\section{Palavras-Chave}

Gabriel García Márquez, Mario Vargas Llosa, história, política, literatura. 


\title{
Introducción
}

\author{
La solidaridad con nuestros sueños \\ no nos haría sentir menos solos, \\ mientras no se concrete \\ con actos de respaldo legitimo a los pueblos \\ que asuman la ilusión \\ de tener una vida propia en el reparto del mundo. \\ (García Márquez, 2014b, p. 212)
}

Lo acometido en este trabajo consiste en recabar los datos de historia económica y política de Colombia que se encuentran como trasfondo a las menciones de la masacre de las bananeras de 1928, en la obra literaria de Gabriel García Márquez. La misma que estudiara Mario Vargas Llosa para su tesis doctoral en la Facultad de Filosofía y Letras de la Universidad Complutense y de la que voy a tomar contenido. Dichos datos permiten hacer el mapa de la vida social-económica del país, con énfasis en una parte concreta de la sociedad colombiana y en un dominio de tiempo específico: el departamento del Magdalena, por un lado, y los principios del siglo XX, por otro. Además de presentar la mecánica extractivista, rentista y utilitaria de capitales extranjeros en una región. Esto me dará ocasión de ampliar el análisis observando lo que Pablo Neruda también manifestó sobre el tema de la explotación de frutas en América Latina. Para ello acudo a su Canto General; me ayudaré de otras obras de arte literarias como La casa grande de Álvaro Cepeda Samudio y de bibliografía complementaria sobre la relación historia y literatura.

Muchos fueron los vectores de investigación que se abrieron cuando hice la investigación publicada con el título Junto a cada pobre me encontrarás cantando. Historia y crítica del fenómeno económico y político en Colombia. El abordado en este artículo, suscrito a la brevedad de la tipología textual presente, es uno de ellos.

\section{El esplendor bananero}

Con el mismo título Mario Vargas Llosa $(1971$, p. 8) introduce una información importante, con motivo de narrar la llegada del coronel Nicolás Márquez y Tranquilina Iguarán a Aracataca -son los abuelos de Gabo, padres de Luisa Santiaga Márquez Iguarán, casada con Gabriel Eligio García, los padres-. Aracataca era un pueblo pequeńo situado en la provincia del Magdalena, al que llegan Nicolás y Tranquilina después de que el coronel hubiera de pelear al lado del general Rafael 
Uribe Uribe en la Guerra de los Mil Días (1899-1902), la misma que dejó al país en quiebra. Muy poco tiempo después y durante el régimen del general Rafael Reyes (1904-1910), la Costa Atlántica colombiana, en donde se encuentra el Magdalena, vivió un brusco crecimiento económico iniciado con el cultivo del banano por toda la cuenca del río Magdalena. A esto se le denomina como la fiebre del banano. Fiebre que, además de ser criolla, abrazó en su calor toda clase de forasteros. Los mismos que eran vistos peyorativamente por las personas de la región, gente "para la que habían acuñado una fórmula despectiva: «la hojarasca»" (Vargas Llosa, 1971, p. 6) ${ }^{1}$.

En este escenario la United Fruit Company regentó la explotación extensiva de las tierras. Para 1908, de cada diez trabajadores agrícolas bananeros, cuatro tenían como patrón a la multinacional. La opulencia económica parecía acompañar a la economía bananera. Vargas Llosa hace cita del imaginario retrospectivo, desde luego posterior a la época, en estas palabras: “(...) «mujeres de perdición bailaban la cumbia desnudas ante magnates, que, por ellas, hacian encender en los candelabros, en vez de velas, billetes de cien pesos»" (1971, p. 8). Así describe Gabriel García Márquez la escena histórica:

Con la Compañía bananera empezó a llegar a ese pueblo gente de todo el mundo y era muy extraño porque en este Pueblito de la costa atlántica de Colombia [se refiere a Aracataca], hubo un momento en el que se hablaba todos los idiomas. La gente no se entendía entre sí; y había tal prosperidad, es decir, lo que entendían por prosperidad, que se quemaban billetes bailando la cumbia. La cumbia se baila con una vela y los simples peones y obreros de las plantaciones de bananos encendían billetes en vez de velas, y esto dio por resultado que un peón de las bananeras ganaba, por ejemplo, 200 pesos mensuales y el alcalde y el juez ganasen 60. Así no había autoridad real y la autoridad era venal porque la Compañía bananera con cualquier propina que les diera, con sólo untarles la mano, era dueńa de la justicia y del poder en general (García Márquez y Vargas Llosa, 1968, p. 23).

La estructura social de la realidad económica tenía la siguiente forma²: en la mitad de dos extremos, que eran, los abuelos, antiguos héroes de guerra y funda-

1 En más lugares también como (Vargas Llosa, 1971, pp. 235-326, 334, 403, 479, 496-497).

2 Es la que reporta Gabriel García Márquez por ejemplo en La hojarasca y en El coronel no tiene quién le escriba. Descripción que se mantiene en esta última, aunque el coronel haya descendido en la escala económica, reemplazado por un "rico", don Sabas, pues todavía desde el punto de vista de la valoración fenomenológica, la gente consideraba y respetaba al oficial por ser fundador de una población y por su participación en hechos históricos importantes. En Los funerales de la Mamá Grande, Gabo conserva la valoración anterior. También en Cien años de soledad. 
dores de poblaciones, y el estrato primero, la hojarasca (dentro de la que se cuenta a los peones de las bananeras), se encontraban los siguientes grupos, en uno de ellos se enmarca a Gabriel Eligio: los telegrafistas, los sastres, los boticarios, los empleados públicos, los artesanos. Estos formaban, como es obvio, una clase media. Paralela a esta, una comunidad endógena, la de los comerciantes extranjeros, sirio-libaneses la mayoría. Los mismos que encontraron buen nicho de mercado en el Magdalena precisamente por la fiebre del banano. Grupo este que perdura todavía en las comunidades de la Costa Atlántica colombiana. Fenómeno iterado en partes concretas de Sudamérica. Había todavía un grupo más, uno inferior: los trabajadores y peones agrícolas. Las tareas de estos oscilaban en el dominio de los oficios urbanos humildes: sirvientes, vendedores ambulantes, recogedores de basuras, camareros de bares, y más. Un subconjunto de este grupo lo conformaban "los vagos, chulos, ladrones, prostitutas, el lumpen o semi-lumpen local" (Vargas Llosa, 1971, p. 106). En otro margen de la sociedad, separados de los anteriores, se encontraban los hacendados, muchos de los cuales eran los ingenieros de las bananeras, la mayoría extranjeros.

La Costa Atlántica colombiana fue en esos primeros veintiocho años del siglo $\mathrm{XX}$, una iteración de un fenómeno latinoamericano casi general: capitales norteamericanos entran en el continente a voluntad y reemplazan los capitales ingleses. Huelga decir que el primer préstamo como nación independiente ocurrió en marzo de 1822, ampliamente conocido como el Empréstito de Zea, firmado en París, con la firma de prestamistas ingleses Herring, Graham \& Powles. Luego, antes de esto, en 1816, Simón Bolívar había negociado en Haití algunos préstamos externos para financiar las primeras incursiones en territorio venezolano en búsqueda de la libertad política y económica con respecto al dominio español. Equipos y materiales como uniformes, fusiles, municiones a los soldados y siete embarcaciones, fue de las que se proveyó para emprender su empresa independista. Un año después, Luis López Méndez y José María del Real, agentes enviados por Bolívar a Europa, consiguieron varios préstamos en casas inglesas privadas con el fin de continuar el proceso contra España. Algunas de esas casas fueron William Hall Campbell, George Robertson, Michael Scott, Pete Edwards y William Graham Junior \& Sons. El interés inglés en el desarrollo de estos acontecimientos es obvio: salir beneficiado de la desmonopolización comercial que traería el éxito independista. Otro ejemplo, de muchos, del paso de los capitales ingleses en el siglo XIX se encuentra en estas líneas:

(...) desde comienzos del periodo republicano los efectos de la [R]evolución [I] ndustrial inglesa y los cambios que la Nueva Granada introdujo en la legislación aduanera para reducir el proteccionismo, hicieron que algunos de los más im- 
portantes sectores artesanales se redujeran rápidamente. De hecho, entre 1822 y 1850 , la tasa anual de crecimiento promedio del volumen de importaciones de telas de algodón inglesas por parte de la República de Nueva Granada fue de $6,9 \%$. Ello fue el resultado de la enorme caída en el precio de los textiles ingleses. Por ejemplo, en términos reales, en 1850 un metro de tela de algodón importado a Nueva Granada valía solo el 55\% del precio que tuvo en 1835 . Es probable que esta sea la razón por la cual ya para esta época los textiles de algodón, especialmente importantes durante la colonia en la Provincia de Socorro, no aparezcan entre los veinte principales productos industriales en 1846. Sin embargo, el artesanado que estaba dedicado a la producción de telas de algodón del país duró algunos años más en desaparecer del todo (...) El efecto de la [R]evolución [I]ndustrial en la industria artesanal colombiana estuvo muy concentrado en la desaparición de la producción local de telas de algodón, que hasta la independencia había sido elemento esencial de la vestimenta de las clases trabajadoras de Nueva Granada (...) (Meisel Roca, 2011, p. 11).

El fenómeno norteamericano tuvo dos vectores: se estableció como hegemonía económica que destruyó capitales menores a su paso, como ocurrió en el Perú con las haciendas de la costa norte, o asimilándoselo como aliado dependiente por parte de los latinoamericanos. Lo que fue el banano en la Costa Atlántica, fue la caña de azúcar, el algodón, el café, el petróleo, los metales, y más, en otros lugares del continente. "La invasión económica norteamericana no tiene oposición e, incluso, es bienvenida porque crea el espejismo de la bonanza" (Vargas Llosa, 1971, p. 10). Fuentes de trabajo, subida de salarios del campesino, impresión de modernización y progreso, son los artículos que pone Vargas Llosa a dicho espejismo. Pero el saqueo de las riquezas naturales como imposición sobre los países latinoamericanos, conexo al impedimento del desarrollo industrial para mantenerlos como fuentes de materias primas, más la aberración de las voluntades políticas por medio de sobornos con el fin de asegurar un resorte jurídico que proteja los propios intereses, son los elementos que los capitales no traen proclamados cuando ingresan. Esto se encuentra bien expresado en varios de los poemas del Canto General de Pablo Neruda. Cito el que titula "La United Fruit Co.":

Cuando sonó la trompeta, estuvo

todo preparado en la tierra

y Jehová repartió el mundo

a Coca-Cola Inc., Anaconda,

Ford Motors, y otras entidades:

la Compañía Frutera Inc. 
se reservó lo más jugoso,

la costa central de mi tierra,

la dulce cintura de América.

Bautizó de nuevo sus tierras como "Repúblicas Bananas," y sobre los muertos dormidos, sobre los héroes inquietos que conquistaron la grandeza, la libertad y las banderas, estableció la ópera bufa: enajenó los albedríos regaló coronas de César, desenvainó la envidia, atrajo la dictadura de las moscas, moscas Trujillos, moscas Tachos, moscas Carías, moscas Martínez, moscas Ubico, moscas húmedas de sangre humilde y mermelada, moscas borrachas que zumban sobre las tumbas populares, moscas de circo, sabias moscas entendidas en tiranía.

Entre las moscas sanguinarias la Frutera desembarca, arrasando el café y las frutas, en sus barcos que deslizaron como bandejas el tesoro de nuestras tierras sumergidas.

Mientras tanto, por los abismos azucarados de los puertos, caían indios sepultados en el vapor de la mañana: un cuerpo rueda, una cosa sin nombre, un número caído, un racimo de fruta muerta derramada en el pudridero (2001, pp. 209-210). 


\section{El conflicto}

El aseguramiento de concesiones y la represión de movimientos de sindicalización y de reivindicación de los trabajadores, son otras de las prácticas clásicas de la explotación de países sobre países. Es precisamente aquí por donde se introduce en este análisis la masacre de las bananeras. Es grande la influencia que tuvo la Revolución Mexicana de 1910 sobre el resto de Latinoamérica en relación con la conformación de movimientos sindicales y luchas obreras. "En los años veinte se fundan sindicatos, centrales de trabajadores, se organizan los primeros partidos anarco-sindicalistas, socialistas y marxistas" (Vargas Llosa, 1971, p. 10). Proceso que fue más demorado en Colombia. Aunque Mario Vargas Llosa afirma que no fue sino hasta 1928 cuando ocurre la primera huelga importante, la de la zona bananera, debe recordarse el dieciséis de marzo de 1918. Guillermo Hernández Rodríguez, prologuista de El pensamiento económico en Jorge Eliécer Gaitán, obra cuidada por Luis Emiro Valencia, dice, sobre aquella fecha, lo siguiente:

El gobierno conservador contrató la vestimenta para el ejército con una compañía extranjera y los sastres de Bogotá, organizados artesanalmente y con el apoyo de los albañiles y de otros grupos sociales, organizaron una gran manifestación de protesta a la cual el régimen respondió a su usanza con abaleo y muerte en la vía pública denominada "Calle de la Carrera». Este hecho cierra un capítulo de las luchas sociales en Colombia con el liderazgo artesanal e inmediatamente se abre otro, en que la figura central son los obreros y campesinos movilizándose colectivamente y con frecuencia organizados en sindicatos y ligas agrarias.

El río de la historia trae a Gaitán sobre este nuevo panorama de luchas sociales.

Su primera presencia parlamentaria, en que se relievan sus condiciones de gran tribuno popular, tiene precisamente lugar a raíz de la gran huelga de las bananeras, explotación regentada por la United Fruit Company. Las fuerzas represivas del régimen conservador de la época, se descargaron sobre los obreros en huelga en forma desordenada y brutal. Gabriel García Márquez describe el drama sangriento en forma resumida pero patética en «Cien años de Soledad». Gaitán, en los debates parlamentarios, con su voz caudalosa y sus tributos de eximio orador, denunció ante la Cámara de Representantes las atrocidades cometidas por el régimen. La defensa de los obreros en esta oportunidad y otras más lo fue constituyendo en su caudillo, en su gran guía y conductor. Es la expresión e interpretación auténtica del pueblo en un tramo dramático de su historia. El anclaje de Gaitán en el partido liberal y el ancho caudal de masas que dentro de dicha colectividad le seguía, le daban el carácter de líder de las nuevas clases en movimiento. Era la expresión, en estratos altos de la vida del país, de las masas nuevas no resignadas a la miseria y ansiosas de un mejor estar y de una influencia política. Varias vertientes conver- 
gían para darle carácter de caudillo del pueblo, como quiera que la masa inmensa de la clase se apretujaba en su torno (Valencia, 2008, p. 13).

Guillermo Hernández menciona Cien años de soledad para introducir la figura de Jorge Eliécer Gaitán y su papel en el marco de las luchas sociales. Dice que la narración de Gabo es resumida y patética, ¿̇a qué se refiere con esto último? A la voz emocionante, conmovedora, agitadora y anímica puesta por el autor a la narrativa del hecho violento de las bananeras. Hay una frase puesta en boca de José Arcadio Segundo, personaje de la novela, que es atómica en ese sentido, la que dice: $; C a-$ brones! Les regalamos el minuto que falta. ¿Cuál es la razón del grito de la figura de la novela? Según el relato de Gabriel García Márquez (1979, pp. 254-255), José Arcadio Segundo es uno de los manifestantes contra la United Fruit Company. Habiendo participado de una reunión con los dirigentes sindicales, le fue puesta la tarea, junto con el coronel Gavilán, de orientar la multitud en huelga. Introduzcamos, antes de seguir la tensión inherente del relato, que Mario Vargas Llosa (1971, p. 10) informa como 1928 el año en el que se fundó, luego del tercer Congreso Obrero Nacional, un Partido Socialista Revolucionario colombiano. Lo que es una imprecisión, pues el partido se creó a la par de dicho congreso, es decir en 1926. De hecho, se puede tirar más atrás, pues en 1924 se sucedió el primer congreso y ya en él empieza su organización. En donde sí es preciso el nobel peruano, es en afirmar que la huelga del año 1928 quedó grabada en las conciencias de la región, por la brutalidad con que fue reprimida por parte del ejército. El jefe civil y militar de la provincia, general Carlos Cortés Vargas, por medio de decreto declaró a los huelguistas como "malhechores" y dio vía libre al ejército para intervenir, "matar a bala". "La matanza se llevó a cabo en la estación de ferrocarril de Ciénaga, donde los huelguistas fueron ametrallados. Murieron muchos y luego se diría que la cifra de víctimas se elevó a centenares o a miles" (Vargas Llosa, 1971, p. 11).

Continuando con la versión en la novela de Gabo (1979), un teniente del ejército se subió al techo de la estación, donde se encontraban cuatro grupos de ametralladoras enfiladas hacia la multitud. Se dio un toque de silencio. Después de cinco minutos, el capitán en tono amenazador, dijo, al ver que la gente no se amenoraba, "un minuto más y se hará fuego". Es aquí donde José Arcadio Segundo "se empinó por encima de las cabezas que tenía enfrente, y por primera vez en su vida levantó la voz". Su grito fue: ;Cabrones! Les regalamos el minuto... Son catorce nidos de ametralladoras las que Gabo pone. Las mismas con las que se respondió sin racionalidad a la orden de fuego dada por el capitán. Muchas voces gritaron al mismo tiempo: “'Tírense al suelo! ¡Tírense al suelo! Ya los de las primeras filas lo habían hecho, barridos por las ráfagas de metralla” (García Márquez, 1979, pp. 254-256). 
En Vivir para contarla, el mismo autor recuerda:

De pronto, mi madre seńaló con el dedo.

-Mira -me dijo-. Ahí fue donde se acabó el mundo.

Yo seguí la dirección de su índice y vi la estación: un edificio de maderas descascaradas, con techos de cinc de dos aguas y balcones corridos, y enfrente una plazoleta árida en la cual no podían caber más de doscientas personas. Fue allí, según me precisó mi madre aquel día, donde el ejército había matado en 1928 un número nunca establecido de jornaleros del banano. Yo conocía el episodio como si lo hubiera vivido, después de haberlo oído contado y mil veces repetido por mi abuelo desde que tuve memoria: el militar leyendo el decreto por el que los peones en huelga fueron declarados una partida de malhechores; los tres mil hombres, mujeres y niños inmóviles bajo el sol bárbaro después que el oficial les dio un plazo de cinco minutos para evacuar la plaza; la orden de fuego, el tableteo de las ráfagas de escupitajos incandescentes, la muchedumbre acorralada por el pánico mientras la iban disminuyendo palmo a palmo con las tijeras metódicas e insaciables de la metralla (2014a, pp. 22-23).

Un niño de apenas cuatro años vivía frente al lugar de la masacre, Álvaro Cepeda Samudio. El mismo que años después sería amigo de Gabriel García Márquez y también habría de recordar el episodio en la novela La casa grande. Obra circunscrita por $\mathrm{Gabo}^{3}$ a un hecho histórico: la huelga de los peones bananeros de la Costa Atlántica, como se ha dicho, resuelta a bala por el ejército. En el libro de Cepeda Samudio, subraya, no hay un solo muerto, y el único soldado que recuerda haber ensartado a un hombre con una bayoneta en la oscuridad, no tiene el uniforme empapado de sangre sino de mierda, también el fusil. Esta es una manera de escribir la historia, aunque a buena parte de los historiadores les despierte suspicacias. A este otro modo lo llama transmutación poética. Cepeda Samudio no elude la realidad ni mistifica la gravedad política y humana del drama social, más bien, dice García Márquez, lo ha pasado por purificación alquímica entregando su esencia mítica, "lo que quedó para siempre más allá de la moral y la justicia y la memoria efímera de los hombres". ¿Acaso esa purificación nos lleva a concluir que matar a un hombre, es llenarse de mierda? ¿Qué significa el uso de esa materia o terminología?

3 Ver contracarátula de (Cepeda Samuadio, 1967). 


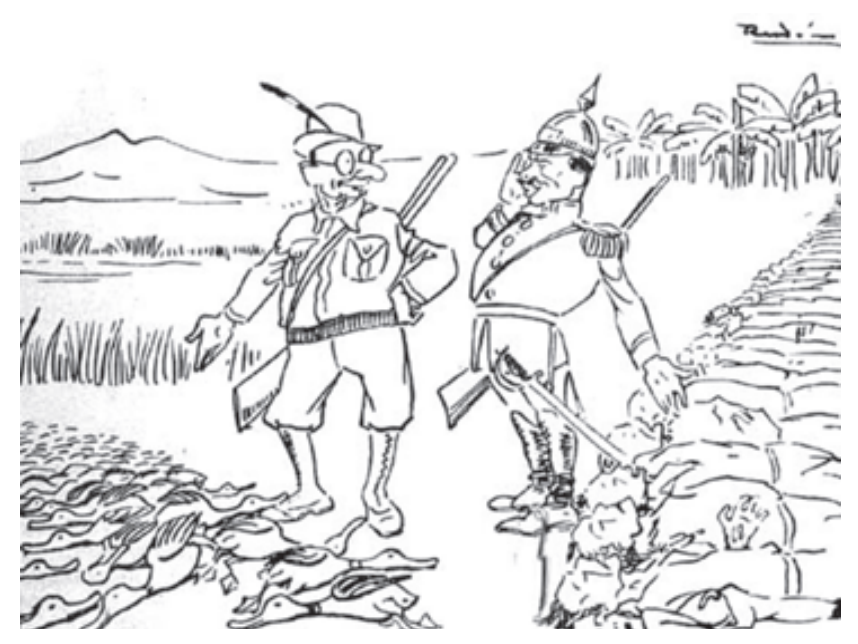

Figura 1. Regreso de la cacería ${ }^{4}$

Este recurso ficcional, como la novela misma, tiene un lugar de enunciación: el ejercicio de violencia política que buscaba sostener el "ecosistema" para el capital extranjero. En dicho ejercicio se llegó a negar la condición humana de los huelguistas. La caricatura de 1929 de Ricardo Rendón (fig. 1) representa al presidente de la República entre 1926-1930, Miguel Abadía Méndez, conservador, y al general del Ejército Carlos Cortés Vargas, de quien salió la orden de abrir fuego en la estación. El primero con ropa deportiva, el segundo con uniforme militar. El uno al otro presenta alineados los cadáveres recogidos. El presidente mató patos, el militar, trabajadores. Si son patos o trabajadores, da lo mismo. Lo que el caricaturista quiere hacer ver es la negación de la condición de ciudadanos de los trabajadores, la negación de los derechos laborales y la banalidad en la que cayó la dignidad humana. La alusión de Cepeda a la mierda como sangre de los trabajadores, tiene como materia intencional de proposición esa realidad.

No ya desde el punto de vista literario, sino desde el biográfico, otras palabras con las que el nobel colombiano recuerda el hecho:

Llegó un momento en que toda esa gente empezó a tomar conciencia, conciencia gremial. Los obreros comenzaron por pedir cosas elementales porque los servicios

4 Disponible en: http://www.banrepcultural.org/blaavirtual/revistas/credencial/octubre1990/ octubre1.htm 
médicos se reducían a darles una pildorita azul a todo el que llegara con cualquier enfermedad. Los ponían en fila y una enfermera les metía, a todos, una pildorita azul en la boca... Y llegó a ser esto tan crítico y tan cotidiano, que los nińos hacían cola frente al dispensario, les metían su pildorita azul, y ellos se las sacaban y se las llevaban para marcar con ellas los números en la lotería. Llegó el momento en que por esto se pidió que se mejoraran los servicios médicos, que se pusieran letrinas en los campamentos de los trabajadores porque todo lo que tenían era un excusado portátil, por cada cincuenta personas, que cambiaban cada Navidad... Había otra cosa también: los barcos de la compañía bananera llegaban a Santa Marta, embarcaban banano y lo llevaban a Nueva Orleans; pero al regreso venían desocupados. Entonces la compañía no encontraba cómo financiar los viajes de regreso. Lo que hicieron, sencillamente, fue traer mercancía para los comisariatos de la compañía bananera y donde sólo vendían lo que la compañía traía en sus barcos. Los trabajadores pedían que les pagaran en dinero y no en bonos para comprar en los comisariatos. Hicieron una huelga y paralizaron todo y en vez de arreglarlo, el gobierno lo que hizo fue mandar el ejército. Los concentraron en la estación del ferrocarril, porque se suponía que iba a venir un Ministro a arreglar la cosa, y lo que pasó fue que el ejército rodeó a los trabajadores en la estación y les dieron cinco minutos para retirarse. No se retiró nadie y los masacraron (García Márquez y Vargas Llosa, 1968, p. 23-24).

Vargas Llosa (1971) comenta estas líneas y hace ver que las anécdotas de la "pildorita azul» y de la "letrina portátil», aunque exageradas, no disminuyen las implicaciones morales y políticas del drama social al que se señala con ellas.

Cuando termina la Primera Guerra Mundial, la fiebre del banano había comenzado a declinar. Desde el punto de vista "frío" de las leyes de la oferta y la demanda, la multiplicación de los cultivos bananeros en otras regiones llevó a la baja de los precios en el mercado mundial. Cuando este proceso se agudizó, las relaciones de comunicación características del intercambio económico empezaron a desaparecer, y junto con estas, terrenos que antes fueron espacio de plantaciones fueron abandonados. La gente se vio cesante y el exilio de la región se convirtió en una opción. En el tope de este devenir transcurrió la primera infancia de Gabriel García Márquez, esto es, cuando ya el paraíso y la crisis habían pasado. El resultado de la oposición entre ambas realidades fue un limbo de miseria, de sordidez y de rutina. Dialéctica que en un nivel inconsciente estuvo presente en la memoria de la gente, y de la cual, la parte paradisiaca, esta sí conscientemente, era usada como "arma para luchar contra el vacío de la vida 
presente" (Vargas Llosa, 1971, p. 13). Aracataca vivía de mitos, de realidades fantasmales, de soledad y de nostalgia por mejores presentes. Elementos que nutrieron la mayoría de la obra literaria de García Márquez.

Cuando nació el nobel colombiano, Aracataca vivía de esos recuerdos. Cerca de la población había una finca de banano que se llamaba Macondo. Nombre que tomará para el mundo que tiene por historia Cien años de soledad. En La hojarasca el esplendor bananero de la región es empleado como episodio histórico que determina el destino de la sociedad ficticia creada en la obra, sociedad que, a todas luces, es también descripción de la sociedad real. Lo mismo ocurre en Cien años de soledad, pero en menor grado, pues la alusión al significado de la fiebre bananera para la región del Magdalena y la llegada de la United Fruit Company, más la ruina que le siguió cuando la fiebre acabó, es "fragmentada", "alusiva" y hasta "oscura" -categorías empleadas por Vargas Llosa (1971, p. 117)-. Una en mayor grado de presentación, la otra en menor, el trasfondo es el mismo: la historia social y económica de una región. En El coronel no tiene quien le escriba, anterior a Cien años de soledad, que tiene como lugar de enunciación también "el pueblo", el banano no es más que una rememoración lejana.

La verdad histórica de estos hechos sociales y económicos no necesariamente se ve empobrecida por la imaginación de las gentes del pueblo. Aunque Vargas Llosa (1971) dice, para el caso, que la fantasía deforma la verdad histórica y los recuerdos de las mismas gentes hierven de contradicciones, no se puede olvidar que la hiperbolización o disminución de los hechos por parte de la experiencia y el entendimiento humanos es ya un dato de historia.

Gabo afirmó de esta historia de economía, política y muerte haberla conocido diez años después de que ocurriera. Cuando escuchaba las versiones, dice el escritor colombiano, unos decían que sí era cierto y otros que no lo era. También algunos decían "Yo estaba, y sé que no hubo muertos; la gente se retiró pacíficamente y no sucedió absolutamente nada". Otros más afirmaban positivamente a la pregunta de si hubo muertos; incluso proclamaban haber estado ahí y haber visto el desastre. Otros apelaban a la confirmación de los muertos y aludían a un familiar que había sido asesinado en el episodio. "Lo que pasa es que en América Latina, por decreto se olvida un acontecimiento como tres mil muertos" (García Márquez y Vargas Llosa, 1968, p. 24). 


\section{Hechos históricos importantes de la zona bananera}

La lista de hechos importantes en la zona bananera es concreta: primero, las guerras civiles anteriores al apogeo económico de la región. Guerras que terminarían con la recordada Guerra de los Mil Días (1899-1902). "Durante el siglo XIX hasta principios del XX en el país se sufrieron nueve guerras civiles" (López, 2015, p. 36). Segundo, el mencionado auge del banano, iniciado hacia 1904, "cuando se instala en la región la United Fruit, y toda la cuenca del Magdalena se llena de fincas y de inmigrantes" (Vargas Llosa, 1971, p. 107). El tercer evento, del que hace también mención Mario Vargas Llosa, es la decadencia. Esta comienza al término la Primera Guerra Mundial y se agudiza al corto plazo en los ańos siguientes. La reducción de los precios del fruto en el mercado mundial hizo que se abandonaran cultivos y fue obvia la subsecuente emigración de personas en búsqueda de otro espacio económico de sobrevivencia. El cuarto, la huelga de los trabajadores bananeros de 1928. La misma que, como se ha escrito, termina con la masacre en Ciénaga. Le agrego a Vargas Llosa, pues cuatro son los puntos enlistados por el peruano. Un quinto y sexto hecho que tienen el carácter de contexto, son los siguientes: la denominada república conservadora que va de 1880 a 1930 y el robo de Panamá en 1903.

Debe recordarse a este respecto que buena parte de los dirigentes colombianos animó la normalización de las relaciones con Estados Unidos después del robo, con el objeto de conseguir ventajas económicas, dado el creciente papel de los Estados Unidos como consumidores del café colombiano, más la posibilidad de recibir inversión de capital norteamericano en el país. Llamo robo al caso Panamá pues comenzando el año 1902 la guerra civil dio un giro cuando el liberal Benjamín Herrera se toma Panamá. La amenaza de esta toma para los intereses conservadores, en buena parte avalados por la política norteamericana, produjo que el gobierno conservador de turno solicitara a Estados Unidos el desembarco de la infantería de marina de ese país en territorio panameño, inmovilizando al general Benjamín Herrera. En el mismo terreno histórico se llevaban a cabo negociaciones con el país del norte para la obtención de derechos para la apertura del canal.

Conversadores y liberales, en pleno conflicto, endulzaban el oído de los negociadores norteamericanos con la promesa de un acuerdo ventajoso, si a cambio apoyaban las ideas de uno u otro bando. El general Rafael Uribe Uribe se vio obligado, después de haber perdido la fe en la victoria, a firmar un tratado de paz con 
el gobierno conservador en el que se aseguraban garantías de amnistía para los liberales. En noviembre de 1902, a bordo del buque norteamericano Wisconsin, Benjamín Herrera firmó el tratado con el cual concluyó la Guerra de los Mil Días. En este berenjenal los panameños se separan apoyados por los Estados Unidos, apenas un año después.

En el año de 1914, en las postrimerías del gobierno de Carlos E. Restrepo, se firmó entre Colombia y los Estados Unidos el tratado Urrutia-Thompson, por el cual se definía entre las dos partes el problema de Panamá. En él se estipulaba una indemnización pecuniaria por parte de los Estados Unidos y que éstos reconocerían su 'sincero pesar' por los acontecimientos. En contraprestación, Colombia daba el asunto por concluido. El parlamento colombiano ratificó inmediatamente el tratado. No sucedió lo mismo en el de Estados Unidos en el cual era influyente aún el círculo de Teodoro Roosevelt y para el cual la cláusula del 'sincero pesar' era una afrenta al pueblo norteamericano. Mientras tanto se habían descubierto en Colombia ricos yacimientos de petróleo y los círculos gobernantes norteamericanos se percataron de que con un poco de presión, y ante la avidez de la oligarquía colombiana por recibir la indemnización, podían presionar con éxito en su favor, la modificación de la legislación petrolera colombiana. Marco Fidel Suárez, quien gobernó al país entre 1918 y 1921, era un político conservador ultramontano dedicado a la gramática. Durante su gobierno se dictó una legislación petrolera en un todo favorable a los intereses norteamericanos. Con ello el presidente gramático no hacía más que desarrollar la teoría expuesta en sus escritos, de una estrecha colaboración con los Estados Unidos expresada en el lema 'hay que mirar al norte', hacia 'la estrella polar'. En el año de 1921 el Presidente Harding presentó al Congreso norteamericano el tratado de 1914 y éste lo aprobó fijando una indemnización de US25.000.000 pero exigiendo que la cláusula del 'sincero pesar' fuera abolida. El presidente Suárez presentó al Congreso colombiano las modificaciones al tratado para que éste las aprobara y ante la agitación producida por las nuevas circunstancias y los ataques que recibía en el parlamento, y con el fin de facilitar la aprobación del tratado, se retiró de la Presidencia. Su sucesor, el Designado Jorge Holguín, nombró como Ministro de Relaciones Exteriores al liberal Enrique Olaya Herrera quien con su habilidad parlamentaria, logró que el tratado fuera aprobado con las modificaciones propuestas por el parlamento americano. Olaya fue premiado con la legación en Washington de donde volvió al país en el ańo de 1930, para inaugurar, como presidente, la república liberal. Con su nombramiento y el de otros prestigiosos abogados liberales quedó consagrada la subsecuente política de gobiernos conservadores que consumaron la entrega de los petróleos colombianos con la colaboración de abogados y financistas liberales. 
El liberal Olaya fue quien como representante diplomático del gobierno conservador, durante la Conferencia Panamericana de La Habana en 1928, apoyó los planteamientos, en el sentido de consagrar la intervención de Norteamérica en los países latinoamericanos (Melo, 1996, pp. 132-133).

\section{¿Realidad real o realidad ficcional?}

En un documental de la televisión británica del año 1990, aparecen estas palabras de Gabriel García Márquez:

Las bananeras es tal vez el recuerdo más antiguo que tengo ... Fue una leyenda, llegó a ser tan legendario que cuando yo escribí Cien años de soledad pedí que me hicieran investigaciones de cómo fue todo y con el verdadero número de muertos, porque se hablaba de una masacre, de una masacre apocalíptica. No quedó muy claro nada pero el número de muertos debió ser bastante reducido... Lo que pasa es que 3 o 5 muertos en las circunstancias de ese país, en ese momento debió ser realmente una gran catástrofe y para mí fue un problema porque cuando me encontré que no era realmente una matanza espectacular en un libro donde todo era tan descomunal como en Cien años de soledad, donde quería llenar un ferrocarril completo de muertos, no podía ajustarme a la realidad histórica... decir que todo aquello sucedió para 3 o 7 muertos, o 17 muertos... no alcanzaba a llenar... ni un vagón. Entonces decidí que fueran 3.000 muertos, porque era más o menos lo que entraba dentro de las proporciones del libro que estaba escribiendo. Es decir, la leyenda llegó a quedar ya establecida como historia (Weldon, 1990).

En efecto, en Cien años de soledad se registra:

José Arcadio Segundo no habló mientras no terminó de tomar el café.

-Debían ser como tres mil -murmuró.

- ¿Qué?

-Los muertos -aclaró él-. Debían ser todos los que estaban en la estación (García Márquez, 1995, p. 375).

En las Conclusiones del artículo con título La novela como historia. Cien años de soledad y las bananeras, Eduardo Posada Carbó notifica que el escritor colombiano reconoció, en 1989, al publicarse la novela sobre Bolívar, El general en su laberinto, que su trabajo no se basaba en datos históricos sino periodísticos. En contraste, a favor de Gabo, Gene Bell-Villada defendió a Cien años de soledad como "la quintaesencia de la historia de América Latina”. Idea esta que, como hace ver el mismo 
Posada Carbó (1998a), remonta a 1952 con Germán Arciniegas, según el cual, la novela latinoamericana es en lo general un documento más exacto que la historia.

En la pugna, si es que en verdad existe, entre realidad real y realidad ficcional, y a partir de la incertidumbre del dato acerca de los muertos, ¿cómo entender al mismo Gabriel García Márquez diciendo que lo escrito por él no es necesariamente literatura, sino expresión de una verdad profunda, de una realidad desesperada (Cobo Borda, 1995)? En el trabajo citado de Posada Carbó se dice que la preocupación allí fue la de averiguar el punto hasta el que llegó la ficción como historia a partir de Cien años de soledad. Insístase en esta idea: América Latina es un continente que tiene por decreto el olvido de un hecho como tres mil muertos (García Márquez y Vargas Llosa, 1968, p. 24). Es decir, el olvido de un número de masacrados tan alto y el número de masacrados tomado en sí mismo, parece fantástico, pero está extraído, como dijo Gabo, de la más miserable realidad cotidiana. Realidad social, realidad política -le agrego-.

La precisión del número no fue un interés de primer orden. Sí lo fue la lectura de la realidad social-histórica. Posada Carbó (1998a) enlista las posiciones de seis críticos literarios que defienden esta idea: 1) Gene Bell-Villada, quien dice: "detrás de la meticulosidad de García Márquez al interpretar la historia y el folclor de su región existe una mayor fidelidad con la misma realidad". 2) Gerald Martin afirma: Cien años de soledad es "una lectura (...) socialista de la historia de Latinoamérica". Lo apocalíptico de la huelga bananera es, a todas luces, histórico. 3) Sthephen Minta, que consideró la narración de la huelga y la masacre como coincidente y aproximada con los hechos conocidos, aunque haya exageración intencional del detalle. ( 4 y 5) Gustavo Alfaro y Lucila Inés Mena argumentando de la descripción de García Márquez, la fidelidad con los hechos. Y 6) Darío Jaramillo Agudelo, haciendo eco del juicio de valoración según el cual la verdad de la historia de Latinoamérica se encuentra en las novelas. Ya desde la aparición de los caucheros en La vorágine de José Eustasio Rivera, de las bananeras en Cien años de soledad, la verdad de la historia ha tenido que ser rescatada por la ficción. ¿Rescatada con respecto a qué? Es la pregunta que se presenta emergente. La respuesta es taxativa: rescatada de la censura y la persecución política a la que en no pocos casos ha sido sometida la narración de la vida de los pueblos.

El mismo Posada Carbó (1998a) destaca tres aspectos que han de ser tenidos en cuenta dentro de las reconsideraciones: el impacto económico y social de la United Fruit Company; la naturaleza represiva del régimen y una entredicha conspiración del silencio que siguió a la huelga, cuyo fin era no hacer expansiva la verdad de la masacre. El autor se concentra en los dos últimos. Para los intereses de este trabajo, 
me enfoco en el último, del primero ya hice tematización. Posada pone en signos de interrogación este último elemento, pues una conspiración del silencio en el seno de la élite política colombiana, cuyo fin era suprimir la verdad de la memoria colectiva, misma tesis sostenida por quienes leen históricamente a Cien años de soledad, no parece tener asidero. Sin embargo, el mismo articulista menciona que los protagonistas involucrados de primera mano en el episodio, no permanecieron callados. El veinte de julio de 1929, uno de los líderes de la huelga, de nombre Alberto Castrillón, desde la cárcel redactó y envió un informe al Congreso, el que se publicara en el mismo año como libro con título 120 días bajo el terror militar. Manuscrito que tuvo hasta repercusión internacional pues la Internacional Comunista calificó el documento, en el que se apelaba a los legisladores para que estos hicieran justicia como representantes de la democracia, como una súplica de un cortesano que implora la indulgencia de la burguesía, y no como el discurso altivo y frontal que debe tener todo revolucionario ferviente de la clase obrera.

El General Carlos Cortés Vargas también se pronunció, pues hizo público un conjunto de explicaciones y justificaciones: Los sucesos de las bananeras.

Mencioné más arriba, citando el escrito de Guillermo Hernández Rodríguez que prologa la obra El pensamiento económico en Jorge Eliécer Gaitán, que Gaitán denunció en el parlamento la masacre (Valencia, 2008). Las acusaciones de este obligaron a Cortés Vargas a responder. Lo hizo en columnas de El Nuevo Tiempo, las mismas que fueran reimpresas por él en el folleto El general Cortés Vargas contesta al representante Gaitán.

Así como Alberto Castrillón en julio de 1929, Víctor Fuentes, alcalde de Ciénaga, responsabilizado como animador de la huelga por el general Vargas, también hizo pública su versión. En 1931 hizo lo mismo Gregorio Castañeda Aragón, un poeta del Magdalena, despachándose en acusaciones contra el general.

Gaitán estuvo en la zona bananera el dieciocho de julio de 1929, durante diez días. Herbert Braun (1985) reporta que el político colombiano, en su regreso a Bogotá, donde pudo se detuvo a denunciar el hecho que había reconstruido a punta de interrogaciones a los naturales del lugar. El tres de septiembre del mismo año, gracias a la iniciativa presentada por el congresista liberal Gabriel Turbay, Gaitán inició un debate en la Cámara que duraría quince días. No pocas personas aguardaban en la plaza de Bolívar el final de cada sesión, y hasta lo acompañaban a su casa después de terminadas. Si hubo conspiración del silencio, la campaña discursiva de Gaitán la evitó. 
Todavía más, Ignacio Torres Giraldo (1978) cuenta que tres abogados del Magdalena, Manuel Robles, Rafael Campo y Lanao Loayza, empezaron a poner luz al horrendo crimen. Los artículos dedicados al tema fueron puestos en la prensa conservadora de Barranquilla, así como en periódicos liberales de Bogotá como El Tiempo. Posada Carbó comenta lo anterior así:

El 14 de septiembre de ese año, después de uno de los debates en el Congreso, el embajador de Bolivia visitó El Tiempo, convertido entonces en los cuarteles de la oposición. Allí Arguedas pudo saludar a Gaitán, "el orador de la tarde", quien estaba al lado de Eduardo Santos, el director del periódico y ya una de las figuras más influyentes dentro del partido liberal. Arguedas pudo también escuchar al congresista Camacho Carreña, quien reconstruía su discurso sobre las bananeras en el Congreso, el que se publicaría, junto con el de Gaitán, al día siguiente en El Tiempo. Las caricaturas, como las de Ricardo Rendón ${ }^{5}$-así como los escritos de otros periodistas y políticos-, también son testimonios de la falta de "silencio" que siguió a los acontecimientos (1998a, pp. 17-18).

De acuerdo con lo informado se colige que el hecho del seis de diciembre de 1928 en Ciénaga, se hizo público con mucha rapidez. Liberales, socialistas y hasta conservadores disidentes lo usaron como bandera para irse en contra del régimen conservador. Uno de esos disidentes fue Pompilio Gutiérrez, quien refiriéndose a Cortés Vargas dijo, en una entrevista para El Espectador del diecinueve de mayo de 1929, que el militar era una "fiera" y que era el responsable del asesinato de mil personas.

Apenas un par de días hacían falta para que se cumpliera un año de la masacre y El Tiempo habría de publicar un informe de Gaitán en el que se imputaba al presidente Abadía toda la responsabilidad constitucional de la matanza de las Bananeras (Gaitán, 1929). Ya el seis, el día del aniversario, el mismo periódico informó "que la Unión Obrera de Colombia, así como otras organizaciones obreras, invitaban a los trabajadores a unirse al 'primer aniversario del salvaje asesinato perpetrado en millares de vidas de nuestros hermanos de la Zona Bananera"' (Posada Carbó, 1998b, p. 412). Del parque Santander salió una marcha de obreros e izquierdistas con dirección al capitolio. Después Felipe Lleras Camargo, miembro de la élite bogotana, simpatizante del socialismo, dio un discurso, el mismo que fue publicado al día siguiente por El Tiempo. Luego se dirigieron al Teatro Mu-

5 Antes cité y representé una. 
nicipal para el lanzamiento de la candidatura presidencial de Alberto Castrillón, como se dijo más arriba, uno de los líderes de la huelga.

Se sabe que uno de los frutos de estos movimientos que no permitieron el silencio de la masacre, fue la remoción del cargo del Ministro de Guerra, Ignacio Rengifo, y del general Cortés Vargas. Huelga decir, remoción que no fue inmediata.

Desde el punto de vista de la publicidad ganada, fue el partido liberal y no el PSR el que se vio mejor beneficiado. Jorge Eliécer Gaitán, por ejemplo, debe gran parte de su fama a las intervenciones en protesta por la matanza. Posada Carbó se arriesga a decir "Perhaps more significantly, the regime did not remain politically immune. On 9 February 1930, a Liberal, Enrique Olaya Herrera, defeated a divided and demoralised Conservative Party, bringing an end to half a century of Conservative hegemony" (1998b, p. 413) [Quizá de mayor significado, el régimen no permaneció políticamente inmune. El 9 de febrero de 1930, un liberal, Enrique Olaya Herrera, derrotaba a un desmoralizado y dividido partido conservador. Se ponía fin así a medio siglo de hegemonía política (1998a, p. 19)].

\section{Conclusiones}

Es verdad lo que dice Posada Carbó (1998b) citando a Alan Knight ${ }^{6}$ : la narrativa de la historia no es equivalente a la de la ficción. Pero no es cierto que el realismo mágico solo sirva en literatura, el realismo mágico no es el beso de la muerte para la historia y las ciencias sociales. En una conferencia de julio de 1923, en Londres, Trevelyan dijo que la poesía de la historia no consiste en la imaginación desbordada, sino en la imaginación que investiga los hechos y controlada por ellos (1924). Posada Carbó (1998b) escribió, frente a esto, que la poesía de Cien años de soledad está basada en la imaginación exagerada de los hechos. Y aunque García Márquez haya admitido no haberse ceñido a la realidad histórica respecto del número de los asesinados en la huelga de 1928, no es cierto que por esto se pueda afirmar que no hubo masacre. Tampoco se justifica que la novela, en este caso concreto Cien años de soledad, tenga que verse a través de ojos con mal brillo como fuente histórica. Mi punto es el siguiente: si la historia se entiende como la narración de la vida de los hombres y de los pueblos, subrayo vida, y la historia tiene que estar pa-

6 Latin America. What Price the Past? An Inaugural Lecture delivered before the University of Oxford on 18 November 1993 by Alan Knight, Professor of the History of Latin America. Oxford: Clarendon Press. 
sando constantemente por el trabajo de la corrección de los juicios, dentro de lo que se incluye limpiar los juicios de exagerada emotividad, no se debe abandonar el hecho de que la historia no se agota en el dato, más bien se extiende, o debería extenderse, al sentido de las cosas. En este orden, 3, 7, 17 o 3.000 muertos sigue siendo una masacre. Lo sigue siendo si se mata un solo hombre, pues lo asesinado en uno no es un cuerpo, un individuo, lo masacrado en uno es la vida entera. Un hombre es la vida, todos los hombres son la vida. John Donne escribió:

Ningún hombre es en sí equiparable a una Isla; todo hombre es un pedazo del Continente, una parte de Tierra firme; si el Mar llevara lejos un Terrón, Europa perdería como si fuera un Promontorio... como si se llevara una Casa Solariega de tus amigos o la tuya propia. La Muerte de cualquier hombre me disminuye, porque soy una parte de la Humanidad. Por eso no quieras saber nunca por quién doblan las campanas; ¡están doblando por ti...! (Hemingway, 1991, p. 13).

¿Acaso esta imagen literaria no es isomórfica con la realidad? ¿Acaso la imagen desbalancea la historia, sea esta tomada como realidad objetiva o como ciencia? De hecho, si viviéramos de acuerdo con esa imagen, no solo entenderíamos mejor la violencia que hemos padecido, sino que aseguraríamos que no se repita.

Recuerdo y conecto en este punto algunas líneas del mismo Gabriel García Márquez: en su discurso de aceptación del Nobel, juzgando la realidad latinoamericana como descomunal, aclaraba que esta realidad no es la del papel, sino la que vive en nosotros y "determina cada instante de nuestras incontables muertes cotidianas" (2014b, p. 168). La misma que sustenta la creación artística de muchos. Poetas, mendigos, músicos, profetas, guerreros y malandrines, "todas las criaturas de aquella realidad desaforada hemos tenido que pedirle muy poco a la imaginación, porque el desafío mayor para nosotros ha sido la insuficiencia de los recursos convencionales para hacer creíble nuestra vida" (2014b, p. 168). La reflexión serena, sin agitación ni ruido, puede permitir "descubrir que nuestra violencia histórica es la dinámica sobrante de nuestra guerra eterna contra la adversidad" (García Márquez, 1996, pp. 11-12), contra lo que es contrario a nosotros. El sentido de las cosas que debe ser reclamado en toda investigación, no solo en la histórica, muestra, para el caso de la violencia y sus modalidades, que lo constituido como sentido en uno que pone en desesperación a otro, o lo masacra, consiste en la valoración según la cual, en la posición según la cual, hay que rechazar la oposición y también toda diferencia. El respeto es siempre el respeto a la diferencia, escribió Estanislao Zuleta, y "solo puede afirmarse allí donde ya no se cree que la diferencia pueda disolverse en una comunidad exaltada, transparente y espontánea, o en una fusión amorosa" (2015, p. 16). El respeto y la diferencia son 
Gabriel García Márquez, Mario Vargas Llosa y la tematización...

difíciles, pero esenciales -quizá por esto mismo son difíciles-. Hay que valorarlos positivamente, sigue Zuleta, "no como un mal menor y un hecho inevitable, sino como lo que enriquece la vida e impulsa la creación y el pensamiento, como aquelo sin lo cual una imaginaria comunidad de los justos cantaría el eterno hosanna del aburrimiento satisfecho" (2015, p. 17).

\section{Referencias}

Braun, H. (1985). The Assassination of Gaitán Public Life and Urban Violence in Colombia. Madison: University of Wisconsin Press.

Castrillón, A. (1974). 120 días bajo el terror militar. Bogotá: Editorial Tupac-Amarú.

Cepeda Samudio, Á. (1967). La casa grande. Buenos Aires: Editorial Jorge Álvarez.

Cobo Borda, J. (Comp.). (1995). Repertorio crítico sobre Gabriel García Márquez. Bogotá: Instituto Caro y Cuervo.

Gaitán, J. (4 de diciembre de 1929). La responsabilidad constitucional del Presidente Abadía en la matanza de las bananeras. El Tiempo.

García Márquez, G. (1955). La hojarasca. Bogotá: Ediciones S. L. B.

García Márquez, G. (1961). El coronel no tiene quien le escriba. Medellín: Aguirre Editor.

García Márquez, G. (1962). Los funerales de la Mamá Grande. Xalapa, México: Universidad Veracruzana.

García Márquez, G. (1967). Cien años de soledad. Buenos Aires: Editorial Sudamericana.

García Márquez, G. \& Vargas Llosa, M. (1968). La novela en América Latina: Diálogo. Lima: Carlos Milla Batres/ediciones Universidad Nacional de Ingeniería.

García Márquez, G. (1979). Cien años de soledad. $3^{a}$ ed. Bogotá: La Oveja Negra.

García Márquez, G. (1995). Cien años de soledad. Barcelona: Mondadori.

García Márquez, G. (1996). Por un país al alcance de lo niños. Bogotá: Villegas Editores.

García Márquez, G. (2007). Cien años de soledad. Bogotá: Norma.

García Márquez, G. (2014a). Vivir para contarla. Bogotá: Penguin Random House Grupo Editorial.

García Márquez, G. (2014b). La soledad de América Latina. Educere, 18(59), 167-170.

García Márquez, G. (2014c). La soledad de América Latina. Cuadernos Americanos: Nueva época, 2(148), 209-214.

Hemingway, E. (1991). Por quién doblan las campanas. Chile: Andrés Bello.

Knight, Alan. (1994). Latin America. What Price the Past? An Inaugural Lecture delivered before the University of Oxford on 18 November 1993 by Alan Knight, Professor of the History of Latin America. Oxford: Clarendon Press.

López López, Andrés Felipe. (2015). Junto a cada pobre me encontrarás cantando. Historia y crítica del fenómeno económico y político en Colombia. Medellín: Editorial Bonaventuriana.

Posada Carbó, E. (1998a). La novela como historia. Cien años de soledad y las bananeras. Boletín Cultural y Bibliográfico. 35(48), 1-19.

Posada Carbó, E. (1998b). Fiction as History: The Bananeras and Gabriel Garcia Marquez's One Hundred Years of Solitude. Journal of Latin American Studies. 30(2), 395-414. 
Meisel Roca, A. (2011). El PIB de la República de la Nueva Granada en 1846: ¿qué nos dice acerca del impacto económico de la independencia? Cuadernos de Historia Económica y Empresarial. (29), 1-28.

Melo, J. (Ed.). (1996). Colombia Hoy. Bogotá: Presidencia de la República.

Neruda, P. (2001). Canto General. España: Planeta DeAgostini S.A.

Torres Giraldo, I. (1978). Los inconformes. 5 vols. Bogotá: Editorial Latina.

Trevelyan, G.M. (1924). History and Literature. History, IX (34), 81-91.

Valencia, L. (1968). Gaitán: Antología de su pensamiento Económico y Social. Bogotá: Suramérica.

Valencia, L. (Ed.). (2008). El pensamiento económico en Jorge Eliecer Gaitán. Bogotá: Desde Abajo.

Vargas Llosa, M. (1971). García Márquez: historia de un deicidio. Barcelona-Caracas: Edición digital: EDCARE (Bufeo) - Colombia/Convenio de coedición Barral Editores, S. A. - Monte Ávila Editores C. A.

Weldon, D. (1990). My Macondo. [Cinta cinematográfica]. Londres/Inglaterra: British Film Institute.

Zuleta, E. (2015). Elogio de la dificultad y otros ensayos. Colombia: Ciencias Sociales Ariel. 